\title{
The Effect of Mindful-START on Quality of Life in Adolescents Who Have Primary Dysmenorrhea
}

\author{
Yuniar Ika Fajarini \\ Doctorate Program of Medical/Health \\ Science, Faculty of Medicine \\ Diponegoro University, Semarang, \\ Indonesia \\ yuniar007@gmail.com \\ Annastaia Ediati \\ Department of Psychology, Diponegoro \\ University Semarang, Indonesia
}

\author{
Akbar Amin Abdullah \\ Department of Nursing, STIKES Duta Gama, \\ Klaten, Indonesia
}

\author{
Noor Pramono \\ Dr. Kariadi Central Hospital Semarang, \\ Indonesia
}

Abstract - Dysmenorrhea can cause women unable to do activities normally and need medication or special treatment. Dysmenorrhea complaints are related to repeated absenteeism at school or in the workplace so that they can interfere with productivity. Despite its high prevalence, primary dysmenorrhea is often treated poorly and is even ignored by health professionals, researchers, and women who may accept it as a normal part of the menstrual cycle. Although primary dysmenorrhea is not lifethreatening, it can have a negative impact on quality of life. The purpose of this study was to analyze the effect of Mindful-START on the quality of life in adolescents who experience primary dysmenorrhea. This study uses an experimental design with a randomized pre-test and a $2 x$ posttest with control group design. 40 respondents in the intervention group were divided into 4 groups doing Mindful-START exercises 6 times in three weeks. Quality of life was measured using the PedsQL Generic Core Scales Version 4.0 questionnaire for children aged 8-18 years. The subject's experience in undergoing mindfulSTART training interventions was explored by the interview method. Data were analyzed using the Wilcoxon test. Significant differences were found between pre- and posttest scores for the respondent that received the intervention $(\mathrm{p}=0.001)$. Posttest scores were significantly higher than pretest scores, suggesting that the intervention was successful. MindfulSTART is expected to be one of the treatments that do not provide side effects and can help reduce menstrual stress and menstrual pain to improve the quality of life in adolescents with primary dysmenorrhea.

Keywords: mindfulness, dysmenorrhea, pain, quality of life, school

\section{INTRODUCTION}

Menstruation is one of the characteristics of maturity in women that usually begins in the teens of 9-12 years [1]. The prevalence of dysmenorrhea in the world is very large, more than $50 \%$ of women in the world experience it [2]. The percentage of dysmenorrhea in the United States is estimated at almost $90 \%$ and $10-15 \%$ of them experience severe dysmenorrhea [3]. The prevalence of dysmenorrhea in Sweden is $72 \%$, and the prevalence of dysmenorrhea in Indonesia is $64.25 \%$ which consists of $54.88 \%$ of primary dysmenorrhea and $9.36 \%$ of secondary dysmenorrhea [4]. Some factors related to primary dysmenorrhea are psychological factors and high prostaglandins [5],[6].

The impact of dysmenorrhea can make a woman unable to move normally and maximally, thus requiring pain medication [7]. Interrupted activity due to dysmenorrhea causes women to experience a decreased quality of life. $4090 \%$ of women where 1 in 13 are affected by dysmenorrhea do not attend work and school for about one day to three days every month [8]. There are 2 ways to reduce dysmenorrhea that is by pharmacology and nonpharmacology [9]. Pharmacological treatment to reduce dysmenorrhea can be done by taking antipain medications (mefenamic acid, proven mothers, methampirone etc.). However, excessive consumption of anti-pain drugs has side effects of liver damage and even hypertension [9]. The simplest non-pharmacological way is to try to divert pain in other activities, warm compresses, adequate sleep, massages, or light exercise [10]. Pain 
management with non-pharmacology is safer to use and does not cause side effects [11-13]. The results of a preliminary study conducted on 7 female students at STIKES Duta Gama Klaten obtained that there were 3 female students reduced dysmenorrhea by sleeping and felt less pain for 50 minutes but then the pain recurred. Three female students overcome dysmenorrhea by taking mefenamic acid drugs and 1 female student reduces pain by drinking warm water, but the pain still recurs too.

The condition of primary dysmenorrhea will get worse if accompanied by unstable psychological conditions, such as stress, depression, anxiety, and excessive sadness [14]. One of the behavioral therapies that can be developed to overcome primary dysmenorrhea caused by stress factors is mindfulness. Mindfulness practice is an alternative in reducing or overcoming concerns about events that have already occurred and events that will come [15]. Mindfulness therapy is proven effective in changing individual problems with the suffering they experience. Suffering experienced by individuals can be in the form of conflict, depression, confusion, stress, and excessive worry. Mindfulness-based training in this research is called Mindful-START which is an abbreviation of mindfulness, S (Stop), T (Take a deep breath), A (Accept), R (Relax and religious), and $\mathrm{T}$ (Thanks).

This training (mindful-START) is a mindfulness action procedure combined with aromatherapy and Benson's relaxation techniques with dhikr. Mindfulness is a lifeenhancing practice that enables us to expand our conscious awareness and general presence. Mindful awareness allows us to become more sensitive to what is occurring in the present moment, both within ourselves and also in the outside world. Some people view mindfulness as a means by which to gain shortterm relief from anxiety, depression or stress, while others presume mindfulness to be a cure for health problems or, a recipe for inner peace and enhanced concentration [15]. The results showed that the high spiritual value was also received by the high-value attention of mindfulness. One way to improve wellbeing is through zikr activities, which are often used as one of psychotherapy in Islam. The individual is conditioned to undertake the activity of realizing the breath coming in and out of his body during remembrance, this condition is fundamental in the practice of mindfulness. Based on the results of another research, there is the influence of dizikir therapy on the reduction of primary dysmenorrhea pain in adolescent girls. Psychoreligious therapy consists of prayer and dhikr to increase endurance (immunity) which will accelerate the recovery process. dzikir and relaxation improve stress perception so that the Hypothalamic Pituitary Adrenal (HPA) axis produces the hormone cortisol in balanced levels. Cortisol at a balanced level will improve various body metabolic processes. In addition to mindfulness and dhikr, aromatherapy can also reduce the level of someone who reduces pain during menstruation. Aromatherapy can provide stimulatory effects, provide a calming sensation, reduce stress, relaxation of the mind and the physical in the body so that it can reduce tension in a person. Essential oil such as lavender will increase alpha waves in the brain and these waves will make the body relax. The effectiveness of mindful-START to overcome dysmenorrhea is not yet known, therefore researchers intend to conduct a study entitled "The Effect of Mindful-START on Quality of Life in Adolescents Who Have Primary Dysmenorrhea". The purpose of this study is to determine the Effect of Mindfulness on Quality of Life in Adolescents Who Have Primary Dysmenorrhea.

\section{METHODS}

This research was a quantitative study, used an experimental design with a randomized pre-test and a $2 \mathrm{x}$ post-test with control group design. The design of this study was used to find The Effect of MindfulSTART on Quality of Life in Adolescents Who Have Primary Dysmenorrhea. Measurements were taken twice, before and after the intervention (pre and post). The effect of the intervention was obtained by measuring differences in the results of the pre-post test. This research was conducted in Institute of Health Science (STIKES) Duta Gama, Klaten. The sampling technique in this study was simple random sampling with the inclusion criteria of the student at STIKES Duta Gama Klaten, a student who experiences dysmenorrhea with regular menstrual cycles, Muslim students and willing to be respondent. While those who were included in the exclusion criteria were respondents who did not come when the study was carried out or respondents who could not participate in the study until completion. The informed consent must be filled in by participants whether they were willing to take part in research activities or not. This study maintained the confidentiality of respondents by not asking respondents to include names but only signatures or the initials on the informed consent.

After the population was determined, the researcher exercised control over the confounding variables to minimize the bias and validity of the research achieved. The research tool used instructional records about mindful-START therapy procedures. Respondents were asked to choose answers about the state of menstrual pain experienced before and after giving mindfulSTART therapy. The

implementation of interventions in this study included a pretest, intervention and post-test. 40 respondents in the intervention group were divided into 4 groups doing Mindful-START exercises 6 times in three weeks. The procedure for mindful-START actions was with 30 minutes of recorded instruction. The time allocated for each meeting was 60-90 minutes and consists of four steps, understanding the problem, how to solve the 
About $70 \%$ of respondents are at the level of severe

problem, determining how to solve the problem and practice the action to solve the problem. Quality of life was measured using the PedsQL Generic Core Scales Version 4.0 questionnaire for children aged 8-18 years. The subject's experience in undergoing mindfulSTART training interventions was explored by the interview method.

Bivariate analysis using a Wilcoxon test was done to determine the differences of Quality of Life (QoL) levels before and after the treatment within group, which the $\mathrm{p}$ value $<.05$ showed a significant differences.

\section{RESULTS AND DISCUSSIONS}

The results of the research that have been carried out are interpreted in the form of tables that will be discussed in accordance with the results that have been obtained, which include:

1. Characteristics of respondents based on age of menarche

Table 1.1 explains that the majority of respondents in the control and intervention group experienced menarche at the age of 12-13 years. Primary dysmenorrhea is menstrual pain that occurs without anatomical genital abnormalities. Primary dysmenorrhea is not associated with pelvic pathology and can occur without organic disease. Primary dysmenorrhea generally occurs in the first 6-12 months after menarche. The intensity of dysmenorrhea can be reduced after pregnancy or at around 30 years of age [14], [15]. This is in line with the results of the study that the majority of respondents who experience primary dysmenorrhea are in the age range of $12-13$ years.

Table 1. 1.Characteristics of respondents based on age of menarche

\begin{tabular}{ccccc}
\hline Age of Menarche & $\begin{array}{l}\text { Control } \\
\text { Gr }\end{array}$ & sup & \multicolumn{2}{c}{$\begin{array}{l}\text { Intervention } \\
\text { Group }\end{array}$} \\
\cline { 2 - 5 } & $\mathrm{f}$ & $\%$ & $\mathrm{f}$ & $\%$ \\
\hline $10-11$ & 30 & 37.5 & 30 & 37.5 \\
$12-13$ & 50 & 62.5 & 50 & 62.5 \\
& & & & \\
\hline & 80 & 100 & 80 & 100
\end{tabular}

2. Distribution of Respondents According to the level of

Primary Dysmenorrhea

Table 1.2 Distribution of Respondents according to the level of Primary

dysmenorrhea

\begin{tabular}{|c|c|c|c|c|}
\hline Level of Primary & & & & \\
\hline Dysmenorrhoea & Lro & ntion_Gro & $\% \mathrm{f}$ & \\
\hline Medium Severe & 11 & 27.572 .5 & 12 & 30 \\
\hline & 29 & & 28 & 70 \\
\hline & 80 & 100 & 80 & 100 \\
\hline
\end{tabular}

pain. Dysmenorrhea is pain that is felt since a few days before the arrival of menstruation. These symptoms are accompanied by pain in the breast, abdominal bloating, headache, back pain, irritability, sleep disturbances and bruising on the thighs and upper arms which arises due to contraction of the myometrial district. Primary dysmenorrhea has nothing to do with gynecological abnormalities, this is pain menstruation that is found without abnormalities in the actual genital organs. Primary dysmenorrhea arises in adolescence, which is about 2-3 years after menarche.

3. Quality of life of adolescents who experience primary dysmenorrhea in the intervention and control groups during

the pre-test

Quality of Life of adolescents who experience primary dysmenorrhea in the intervention and control groups before the intervention was analyzed frequently. The analysis results are presented in the following table:

Table 1.3. Quality of Life of adolescents who experience primary dysmenorrhea in the intervention and control groups during the pretest

\begin{tabular}{ccccc}
\hline Quality of Life & \multicolumn{2}{l}{$\begin{array}{l}\text { Intervention } \\
\text { G }\end{array}$} & roup & \multicolumn{2}{c}{ Control Gr sup } \\
\cline { 2 - 5 } & $\mathrm{f}$ & $(\%)$ & $(\mathrm{f})$ & $(\%)$ \\
\hline Poor & 25 & 62.5 & 26 & 65.0 \\
Good & 15 & 37.5 & 14 & 35.0 \\
\hline & 40 & 100 & 40 & 100 \\
\hline
\end{tabular}

Table 1.3 explains that the quality of life of adolescents who experience primary dysmenorrhea in the intervention group and the control group is mostly in the severe category of $62.5 \%$ in the intervention group and $65 \%$ in the control group (pretest).

4. Quality of life of adolescents who experience primary dysmenorrhea in the intervention group and the control

group at the post test

Table 1.4 Quality of life of adolescents who experience primary dysmenorrhea in the intervention group and the control group at the post

\begin{tabular}{ccccc}
\hline test & \multicolumn{3}{l}{ Control Group } \\
\cline { 2 - 5 } & Quality of Life & \multicolumn{2}{c}{ Intervention Group } & \multicolumn{2}{c}{ f } & $\%$ & $\mathrm{f}$ & $\%$ \\
\cline { 2 - 5 } & 13 & 32.5 & 24 & 60.0 \\
Poor & 27 & 67.5 & 16 & 40.0 \\
Good & & & & \\
\hline & 40 & 100 & 40 & 100
\end{tabular}

Table 1.4 explains that the quality of life of adolescents who experience primary dysmenorrhea in the 
Table 1.5 Differences in the Quality of Life of adolescents who experience primary dysmenorrhea in the intervention and control groups at the post test

the control group is in the poor category $(60.0 \%)$. Mindful-START is a combination of mindfulness, aromatherapy, and Benson's relaxation techniques which are able to reduce the scale of primary dysmenorrhea. When the pain decreases, quality of life can be improved. One of the benefits of mindfulness is reducing pain. The nature of mindfulness or one's tendency to be mindful will correlate with lower pain sensitivity, and the deactivation of brain circuits which is called default mode networks will be higher. The default mode network consists of several areas of the brain that are interconnected and active in a state of rest - that is, when someone is not paying attention to the outside world which stimulates attention and focuses on their internal state. Several major brain areas that make up this network include the posterior cingulate cortex, medial prefrontal cortex, and angular gyrus. Previous studies have shown that meditation reduces activity in this network. This study found that higher mindfulness was correlated with greater deactivation of the posterior cingulate cortex. People who have a tendency to mindfulness also feel less pain. The intervention group experienced a decrease in pain scale. Benson's relaxation techniques will affect the sympathetic and parasympathetic nervous system, causing muscles to relax and pain to be reduced. Benson's relaxation is relaxation that involves beliefs followed by an acceleration of the state in order to be relaxed (a combination of relaxation and belief). Benson's relaxation will multiply the benefits (because it is added with belief) compared to just using the relaxation response. In addition to Benson's relaxation and mindfulness, aromatherapy has the benefit of reducing the intensity of dysmenorrhea experienced. Lavender is one of the effective non-pharmacological pain management. Giving aromatherapy lavender is not only easy for women but also does not have side effects. Treatment of dysmenorrhea is done by giving lavender aromatherapy inhalation. Lavender has a calming effect. It can provide calm, balance, comfort, taste openness and confidence. It can also reduce stress, emotional imbalance, hysteria, frustration and panic. Lavender can be beneficial for reducing pain and can provide relaxation.

5. Differences in the Quality of Life of adolescents who experience primary dysmenorrhea in the intervention and

control groups

The difference in the quality of life of adolescents who experience primary dysmenorrhea at the pre-test and posttest in the control group and the pre-test and posttest in the intervention group is implemented using the Wilcoxon test. The results of the analysis can be seen in the following table:

\begin{tabular}{l}
$\begin{array}{c}\text { Differences in the } \\
\text { Quality of Life }\end{array}$ \\
\hline Post-test control 402 (1-3) 0,001 post-test intervention 401 (1- \\
2)
\end{tabular}

Table 1.5 analysis results show that the p-value is 0.001 . $\mathrm{P}$ value $<0.05$ can be concluded that there is a significant difference between the control group and the intervention group. According to the basis of decision making in the Wilcoxon test, it can be concluded that $\mathrm{Ho}$ is rejected, and $\mathrm{Ha}$ is accepted. The results indicate that there is a significant effect of mindful-START training on improving quality of life in adolescents who experience primary dysmenorrhea.

In this study, it was explained that the quality of life of adolescents before being given Mindful-START training was in the poor category. Research that has been done showed that dysmenorrhea could reduce the quality of life of a woman. For example, students who experience dysmenorrhea will decrease their learning concentration due to menstrual pain felt [16]. If a student experiences dysmenorrhea, their learning activities at school are disrupted and this often makes them absent from school [17]. In addition, the quality of life decreases. For example, a student who experiences dysmenorrhea cannot concentrate on learning and her motivation to learn will decrease because of the dysmenorrhea felt during the teaching and learning process [18], [19]. Through this mindfulSTART procedure, the participants are expected to be able to interpret the positive and negative events so that they can be grateful for the pleasure given by God. They can overcome feelings of anxiety and improve their well-being by increasing the self-awareness of the therapeutic participants [20,21]. This spiritual support (Relax and Religious) can help or overcome extraordinary physical difficulties so as to increase success in treatment [22],[23]. This fact can answer the question why the quality of life of adolescents who experience primary dysmenorrhea in the intervention group at the time of the post-test majority is in the good category $(67.5 \%)$. However, in the control group, the majority is in the poor category $(60.0 \%)$.

The diagnosis of dysmenorrhea in this study was a limitation of the study. In addition to anamneses, the diagnosis of primary dysmenorrhea was based on physical and gynecological examinations and supporting examinations in order to examine anatomic abnormalities and pelvic area diseases. The process to determine the type of dysmenorrhea in this research was formulated using the Naïve Bayes method calculation from research data and based on expert knowledge. (no physical and gynecological 
[3] Harlow SD, Park M. A longitudinal study of risk factors for the occurrence, duration and severity of menstrual cramps in a cohort of college women. $\mathrm{Br} \mathrm{J}$ Obstet Gynaecol 1996; 103:1134e42.

[4] Beddu S, Mukarramah S, Lestahulu V. Hubungan Status Gizi dan Usia Menarche dengan Dismenorea Primer Pada Remaja Putri. The Southeast Asian Journal of Midwifery [internet]. 2015 [cited: 2017 Sept 15]: 1(1).

[5] Kritz-Silverstein D, Wingard DL, Garland FC. The association of behavior and lifestyle factors with menstrual symptoms. J Womens Health Gend Based Med 1999;8:1185e93.

[6] Chen C, Cho SI, Damokosh AI, et al. Prospective study of exposure to environmental tobacco smoke and dysmenorrhea. Environ Health Perspect 2000;108:1019e22.

[7] Iacovides S, Avidon I, Baker FC. What we know about primary dysmenorrhea today: a critical review. Hum Reprod Update 2015;21:762e78.

[8] Balik G, Ustuner I, Kagitci M, et al. Is there a relationship between mood disorders and dysmenorrhea? J Pediatr Adolesc Gynecol 2014;27:371e4.

[9] Ali Z, Burnett I, Eccles R, et al. Efficacy of a paracetamol and caffeine combination in the treatment of the key symptoms of primary dysmenorrhoea. Curr Med Res Opin 2007;23:841e51.

[10] Twigg J. Dysmenorrhoea. Curr Obstet Gynaecol 2002;12:341e5.

[11] Wu LL, Su CH, Liu CF. Effects of noninvasive electroacupuncture at Hegu (LI4) and Sanyinjiao (SP6) acupoints on dysmenorrhea: a randomized controlled trial. J Altern Complement Med 2012;18:137.

[12] Laufer MR. Helping "adult gynecologists" diagnose and treat adolescent endometriosis: reflections on my 20 years of personal experience. J Pediatr Adolesc Gynecol 2011 Oct:24(5 Suppl):S13-7. http://dx.doi.org/1 0.1016/j.jpag.2011.07.005.

[13] Coco AS. Primary dysmenorrhea.

Am Fam Physician
1999;60:489e96.

[14] Alonso C, Coe CL. Disruptions of social relationships accentuate the association between emotional distress and menstrual pain in young women. Health Psychol 2001;20:411e6.

[15] Dhlman S. Mindfulness and the art of living creatively: Cultivating a creative life by minding our mind. Journal of Social Change. 2012;4(1):24-33

[16] Iglesias EA, Coupey SM. Menstrual cycle abnormalities: diagnosis and management. Adolesc Med 1999;10:255e73.

[17] Banikarim C, Chacko MR, Kelder SH. Prevalence and impact of dysmenorrhea on Hispanic female adolescents. Arch Pediatr Adolesc Med. 2000;154:1226e9.

[18] Emans SJ, Laufer RL, Goldstein DP. Pediatric and adolescent gynecology. ed 5. Philadelphia: Lippincott, Williams \& Wilkins; 2005.

[19] Rogers HB. Koru: Teaching mindfulness to emerging adults. New Directions for Teaching and Learning. 2013;134:73-81.

[20] Rogers HMM. Mindfulness for the next generation: helping emerging [23] Segal ZV, Williams JMG, Teasdale JD. Mindfulness-based cognitive adults manage stress and lead healthier lives. New York: Oxford therapy for depression: a new approach to preventing relapse. New University Press; 2012.

[21] Stahl B, Goldstein E. A mindfulness-based stress reduction [internet].2016:4(1).jurnal.untan.ac.id/index.php/justin/article/vi ew/12 workbook. Oakland, CA: New Harbinger Publications; 2010. 326

[22] Linehan M. Skills training manual for treating Borderline Personality York: Guilford Press; 2002.

[23] Nurfarianti N, Tursina, Anggi S. Sistem Pakar untuk Diagnosis Disorder. New York: Guilford Press; 2003.

[2] Parazzini F, Tozzi L, Mezzopane R, et al. Cigarette smoking, alcohol consumption, and risk of primary dysmenorrhea. Epidemiology 1994;5:469e72. 